\section{Posible efecto de las estatinas sobre los niveles séricos de vitamina $D$ en pacientes con enfermedad renal crónica}

\section{Possible effect of statins on serum vitamin D levels in patients with chronic renal disease}

\section{Sr. Editor}

La enfermedad renal crónica (ERC) representa un problema de salud pública mundial, ya que la prevalencia y la mortalidad están aumentando significativamente ${ }^{1}$.

Uno de los factores que se asocia con el crecimiento de la mortalidad en pacientes con ERC es la dislipidemia ya que participa de manera activa en la patogenia de la enfermedad cardiovascular (causa principal de muerte en ERC) y produce deterioro de la función renal ${ }^{2}$. Por ende, el manejo tiene como meta llevar los niveles de colesterol LDL (CLDL) a cifras menores de $100 \mathrm{mg} / \mathrm{dl}^{2}$.

Para lograrlo, las guías de la National Kidney Fundation (K/DOQI) designan a los inhibidores de la hidroximetilglutaril coenzima A reductasa (HMG-coA inhb), también llamados estatinas, como medicamentos de primera línea, que actúan a nivel hepático al inhibir el paso de HMG-coA a ácido mevalónico, lo cual coarta toda la cascada de generación de colesterol (fig. 1) y, por ende, disminuye la producción de cLDL (3).

Estos fármacos son de primera elección por su eficacia en la disminución de cLDL y por la seguridad de su uso ${ }^{3}$. No obstante, dichas características no excluyen a los pacientes de no padecer miotoxicidad o hepatotoxicidad, efectos adversos más comunes de las estatinas, si bien se reporta una baja posibilidad de desarrollarlos ${ }^{4}$.
A raíz de este punto, el grupo investigador plantea que el uso de estatinas no solo produce miotoxicidad y hepatotoxicidad, sino que a su vez podría generar deficiencia de otras sustancias dependientes de colesterol ante su inhibición, y por tanto proponen el caso de la vitamina $D$, prohormona que se obtiene a partir de la producción de 7-dehidrocolesterol, compuesto antecesor del colesterol que se produce en el hígado (fig. 1). Este compuesto se deposita en la dermis y una vez que los rayos ultravioleta tienen contacto con la piel, genera colecalciferol (D3), compuesto imprescindible en el metabolismo del hueso en el cuerpo $^{5}$.

De acuerdo con el alcance fisiológico descrito previamente sobre el metabolismo del colesterol y la vitamina D se observa que ambos comparten una misma vía metabólica (fig. 1); por ende, se cree que es posible que exista una alta frecuencia de disminución de vitamina $D$ en pacientes con enfermedad renal crónica que utilizan estatinas para el tratamiento de la dislipidemia, ya que al inhibir la producción de colesterol en el hígado, la producción de 7-dehidrocolesterol podría estar disminuida, fenómeno que generaría una concentración baja de vitamina $D$ en el organismo. Esta situación podría empeorar la condición de estos pacientes, ya que en ellos existe una disminución de la actividad de la 1-alfa-hidroxilasa necesaria para la activación de la vitamina $D$ en el túbulo contorneado proximal ${ }^{2}$. Sin embargo, no se han encontrado reportes de investigación que demuestren que existe asociación causal entre el uso de estatinas y niveles bajos de vitamina D. Por tal motivo, esta carta está dirigida a generar nuevas investigaciones con base en la pregunta de si existe asociación entre la disminución de los niveles de vitamina $D$ y el uso de estatinas en pacientes con enfermedad renal crónica, ya que esta sería una relación que podría redireccionar el tratamiento de la dislipidemia. 


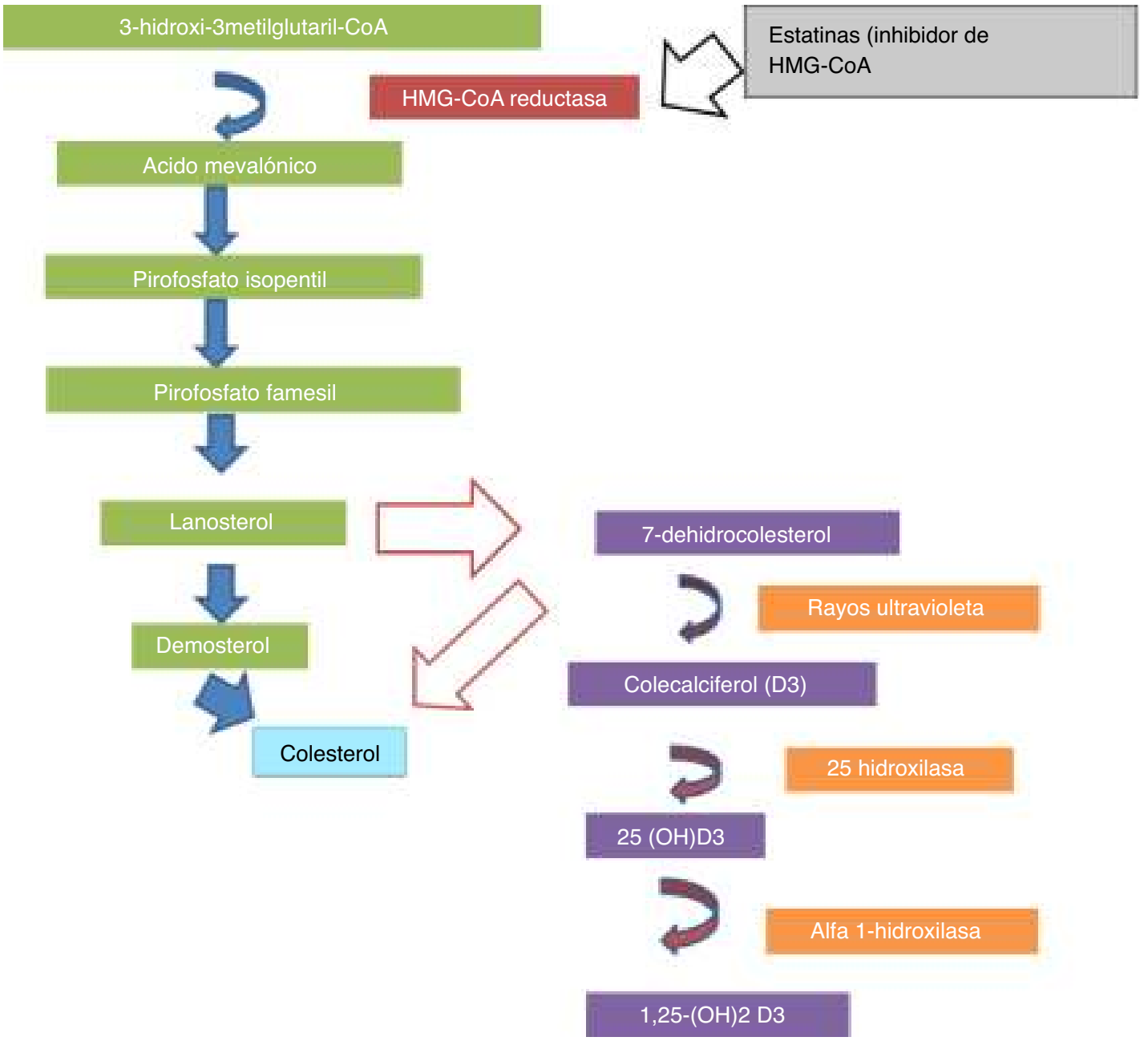

Figura 1 Posible relación entre el uso de estatinas y la concentración de vitamina D (5).

\section{Bibliografía}

1. Tsimihodimos V. Dyslipidemia associated with chronic kidney disease. TOCMJ. 2011;5(1):41-8.

2. Tsimihodimos V, Dounousi E, Siamopoulos K. Dyslipidemia in chronic kidney disease: an approach to pathogenesis and treatment. Am J Nephrol. 2008;28(6):958-73.

3. $\mathrm{K} / \mathrm{DOQ}$ clinical practice guidelines for managing dyslipidemia in chronic kidney disease. Am J Kidney Dis. 2003;41Suppl 3: S1-237.

4. Flores C, Alvo M, Borja $\mathrm{H}$, Morales J, Vega J, Zúñiga C, et al. Enfermedad renal crónica: Clasificación, identificación, manejo y complicaciones. Rev Méd Chil. 2009;137(1): 137-77.
5. Baggerly CA, Cuomo RE, French CB, Garland CF, Gorham ED, Grant WB, et al. Sunlight and vitamin D: necessary for public health. J Am Coll Nutr. 2015:1-7.

\section{José Palacios-Flores*, Ximena Vega-Arias y Pedro Ángeles-Abanto}

Medicina Universidad Peruana de Ciencias Aplicadas de Lima, Perú

* Autor para correspondencia.

Correo electrónico: jpf.260389@gmail.com (J. Palacios-Flores). 